\title{
Arteterapia y Fibromialgia: Las Resistencias del Dolor
}

\author{
Araceli GuIOTE GONZÁLEZ ${ }^{1}$ \\ aguiote@hotmail.com
}

Recibido: $29 / 06 / 12$

Aceptado: $22 / 11 / 12$

\section{RESUMEN}

En este texto, voy a exponer un estudio de caso de una mujer, que sufre de fibromialgia.

Forma parte de un proceso de investigación doctoral, en el cual intervienen diferentes instituciones: la Universidad de Ciencias de Educación y Bellas Artes de Granada; Universidad Complutense de Madrid y The Goldsmiths College.

La finalidad de la metodología del estudio de caso en este proyecto, es construir estudios de casos con orientación teórica psicoanalítica, que nos permitan entender mejor el síndrome de la fibromailgia y por tanto posibilitar mediante la investigación una mayor eficacia de su tratamiento desde el arteterapia. Así mismo, el objetivo de este artículo, es posibilitar nuevas aperturas de pensamiento, por el cual, poder entender desde enfoques nuevos y poco explorados hasta el momento, un estado de enfermedad que si bien hasta hoy día nada se puede decir a ciencia cierta, sí se puede reflexionar sobre procesos de formación psíquicos que no son únicos en la fibromialgia, sino que, también pueden ser encontrados, la clínica psicosomática y género

Palabras clave: Fibromialgia, Cuerpo, Resistencias, Límites, Somatización, Dolor.

\section{Referencia normalizada}

Guiote González, A. (2012). “Arteterapia y Fibromialgia: Las Resistencias del Dolor”. En Arteterapia: Papeles de arteterapia y educación artística para la inclusión social Vol.7: páginas 261-278. Madrid. Servicio de publicaciones UCM.

\section{SUMARIO}

Encuadre. Centro. Tarea. Tiempo Institucional. Tiempo Sincrónico. Participantes. Estructuración de los talleres. Estrategias de recogida de información. Objetivos generales del cuerpo teórico de la investigación. Objetivos e Hipótesis del cuerpo práctico de la investigación. Estudio de caso. Conclusiones. Bibliografía.

\section{Art therapy and Fibromyalgia: the resistance of the pain}

In this text, I will present case study of a woman who suffers from fibromyalgia.It is part of a process of doctoral research. The research project involved the University of Sciences of Education and Fine Arts of Granada; Complutense Madrid University and The Goldsmiths College. The project consists of three phases.

\footnotetext{
${ }^{1}$ Doctoranda en Arteterapia; Arteterapeuta; Licenciada en Historia del Arte; Docente en el Máster en Arteterapia y Aplicaciones del Arte para el Diálogo y la Integración Social, Universidad Pablo de Olavide, (Sevilla); Docente en mesas redondas en diversas jornadas y congresos de arteterapia, nacionales e internacionales. Publicaciones en revistas especializadas en el campo de la salud. Miembro de Afia (Asociación Foro Iberoamericano de Arteterapia) y miembro de la FEAPA (Federación Española de Asociaciones Profesionales de Arteterapia).
} 
The purpose is to build with theoretical guidance case studies in the clinic of psychoanalysis that allow us to better understand this disease and therefore enable research greater effectiveness its treatment from arttherapy. The aim of this article is to provide new openings of thought, whereby, to understand from new and little explored approaches so far, a state of disease, in which, although until today day anything can be said with certainty, it is possible reflect on training mentally they are not unique to fibromyalgia, they can also be found, psychosomatic clinic and gender.

Keywords: Fibromyalgia, Body, Resistors, Límits, somatizatión, pain.

\section{CONTENTS}

Setting. Center. Task. Institutional time. Synchronous time. Participants. Structuring of the workshops. Strategies for collecting information. Objectives generals of the theorical body of research. Objectives and hypotheses of the practical body of research. Case study. Conclusions. Bibliography

\section{ENCUADRE}

\section{CENTRO}

Asociación Agrafim. (Asociación Granadina de Fibromialgia): Es una asociación sin ánimo de lucro, se constituyó en Granada el día 20 de Diciembre del 2000.

\section{TAREA}

Permitir que las participantes trabajen creativamente para alcanzar el nivel más alto de expresión dentro de sus respectivos marcos físicos y psicológicos.

Fomentar la búsqueda de creación de símbolos que representen las condiciones internas y externas y su representación en una estructura visual.

\section{TIEMPO INSTUCIONAL}

Las participantes pueden disponer de las actividades e instalaciones del centro desde las 10 de la mañana hasta las 8 de la tarde.

\section{TIEMPO SINCRÓNICO}

Los talleres de arteterapia, tenían lugar dos veces a la semana. Dos horas de duración, durante tres meses, realizándose un total de 23 talleres.

\section{PARTICIPANTES}

Tres participantes. Se va a exponer información de solo un estudio de caso.

\section{ESTRUCTURACIÓN DE LOS TALLERES}

Los talleres se estructuraban en tres partes: Una primera parte, para hablar sobre el trabajo de obras anteriores o hablar de cualquier cosa que surgieran en los talleres. Segunda parte, el proceso creativo. Tercera parte, un espacio para que cada participante exponga su trabajo y hable de manera libre sobre el proceso, materiales, etc.

\section{ESTRATEGIAS DE MUESTREO DE RECOGIDA DE LA INFORMACIÓN}

A continuación detallaré brevemente, cómo se ha intervenido en éste proceso de investigación en arteterapia: enfoques, métodos, estrategias para la recogida de información, etc... 
Este estudio tiene una orientación de trabajo basada en las artes, es cualitativa y se denomina "investigación acción". Para aplicar la investigación acción, previamente se ha realizado un análisis conceptual, desde la cual, se ha elaborado un registro cualitativo de categorías de trabajo que se desea y espera obtener información. Este registro es un proyecto "piloto" y se usa como estrategia de obtención de información cualitativa para planear futuras intervenciones o acciones en arteterapia con fines de transformación terapéutica en las participantes. Se ha seleccionado las siguientes metodologías de investigación: estudio de casos y heurística. Y las estrategias de recogida de información son: registro cualitativo, notas de observación de los talleres; diario artístico por parte de las participantes; entrevista semiestructurada, cuestionario a mitad de los talleres, análisis fenomenológico de las obras; procedimientos interpretativos de carácter heurístico, hermenéutico, sustentativo (vinculado a la growded theory); uso de la propiedad de la interpretación y a una definición racional del arte que incluyen habilidades que permiten trabajar con los componentes visuales y verbales de manera simultánea.

\section{OBJETIVOS GENERALES DEL CUERPO TEÓRICO DE LA INVESTIGA- CIÓN}

Fundamentar una metodología desde la disciplina del arteterapia, con efectos terapéuticos en la paliación y disminución del dolor en el colectivo de la fibromialgia.

\section{OBJETIVOS DEL CUERPO PRÁCTICO DE LA INVESTIGACIÓN}

Fomentar las posibilidades de autonomía en la mejora y rehabilitación de pacientes con Fibromialgia.

Posibilitar la reestructuración interiorizada de la imagen corporal dolorida.

Proporcionar herramientas óptimas a través de la expresión creativa, para una efectiva autogestión del dolor.

Aliviar el dolor mediante una mayor toma de conciencia de su estado corporal y emocional.

Utilización de los talleres como medios para canalizar las emociones bloqueadas y de malestar en la subjetividad de las participantes.

Conectar y escuchar al cuerpo de una manera diferente al dolor, mediante la expresión artística.

Orientar el uso del arte en su capacidad para presentar de manera organizada aspectos parciales de la propia subjetividad.

Construir otras vías de comunicación con uno mismo y los otros, alternativas a la palabra.

Ligar el trabajo de la creatividad con la función de "reparación", entendiendo la obra como una "re-creación".

\section{HIPÓTESIS DE TRABAJO}

¿Puede el arteterapia ser un tratamiento complementario y eficaz a un tratamiento médico en la disminución de la sintomatología del dolor? 
¿Puede el arteterapia ser un medio terapéutico que posibilita la disminución y alivio del dolor en mujeres que sufren la fibromialgia, mediante una toma de conciencia de características propias del síndrome y de su subjetividad?

\section{ESTUDIO DE CASO}

Uno de los objetivos del estudio de caso en esta investigación sigue la orientación de (Flybjer, 2004) es narrar la evolución de los talleres desde las diferentes perspectivas: a modo individual de cada participante, a modo grupal y también la perspectiva del arteterapeuta; en la cual se expone al lector, reflexiones sobre cómo recibieron ellas las acciones en arteterapia, y para ello recupero sus propios discursos y sus propias notas para remitirlas lo más fidedignamente posible.

En la reflexión y narrativa de la exposición, se tiene muy en cuenta la literatura existente, desde donde se refuta o compara similitudes y diferencias. Este texto está lejos de pretender ofrecer interpretaciones cerradas del sufrimiento en la subjetividad femenina que sufre el síndrome, sino que manifiesta un deseo primordial de ofrecer "posibilidades de pensamientos", en el cual, se invita al lector a pensarlas y se le hace partícipe de acercarle a mi propio proceso de aprendizaje y entendimiento, en este viaje hacia la subjetividad del dolor humano. Las referencias, citas, y reflexiones que se exponen a lo largo de la narrativa, deben de ser recogidas por parte del lector como una pequeña parte dentro de un fenómeno de estudio mayor, complejo y abierto, en el cual, coexisten muchos factores que en este espacio no se pueden abarcar. El principal objetivo de este estudio de caso, es contar la historia en su diversidad, desplegándola desde muchos lados, compleja y muchas veces conflictiva como las propias participantes lo contaron en su paso por los talleres.

Tengo un especial interés en insistir en estas cuestiones, porque hay fragmentos del texto donde yo, tanto como investigadora y arteterapeuta, puedo plantear reflexiones contrastándolas con la literatura, pero el fin de este texto es que el estudio de caso pueda ser diferente para diferentes personas; no intenta ofrecer una verdad escondida detrás de los párrafos, o un único camino sobre "causalidades del síndrome", sino exponer lo acontecido en la práctica arteterapeutica desde un abanico abierto de posibilidades mediante las diferentes perspectivas y análisis de enfoques que se han abordado; y finalmente, será tarea del lector de descubrir su propio sendero y la verdad dentro del caso.

El estudio de caso forma parte de unos talleres que se llevaron a cabo con un total de tres participantes. La participante A es una mujer de unos 65 años, que ha sufrido durante más de veinte año la fibromialgia y otras enfermedades como artrosis reumatoide, degeneración de los huesos. Durante todo ese tiempo ha sido sometida a operaciones para las articulaciones de las piernas, $\mathrm{y}$ ha estado bajo tratamiento farmacológico. Adentró como socia en la asociación desde los inicios de la misma y ha estado recibiendo diferentes tipos de tratamientos para paliar la sintomatología del dolor crónico entre otras sintomatologías y los tratamientos fueron: fisioterapia, talleres para la memoria, autoayuda, reforzamiento para afrontar la enfermedad, curso de fotografía, biodanza, natación, entre otras actividades. 
En los talleres de arteterapia a veces se trabajaba desde unas consignas asignadas, otras solo desde las sugerencias del material y en otras ocasiones, se promovían acciones artísticas.

Durante las primeras sesiones, a la participante A se le despertó el deseo de aprender las técnicas de materiales de arte y dichos deseos se fueron incrementando conforme evolucionaron los talleres.

En los dos primeros talleres, manifestó una necesidad de copiar, en uno de ellos a la compañera y en el otro, mediante el uso de una imagen fotográfica. En la primera sesión, se trabajó con la propuesta "expresar ideas o cosas que nos gusten". Hay dos características llamativas en ésta obra: la primera de ellas, la similitud y copia de elementos realizados por su compañera y la segunda, cuando se le preguntó a la participante por la relación entre la propuesta de trabajo y su obra realizada, ella respondió mediante una descripción de los deseos de su madre, a quién ha representado plásticamente en un tamaño jerárquico mayor en el centro de la composición. Fue difícil acceder al reconocimiento de si había algún deseo suyo en la obra, finalmente concluyó que sus deseos podían ser los que están en una esquina, el mar, representado en un tamaño pequeño.

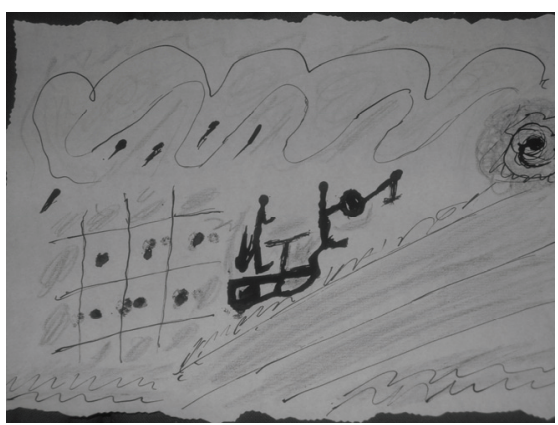

Imagen 1 ¿La huida de dolor?

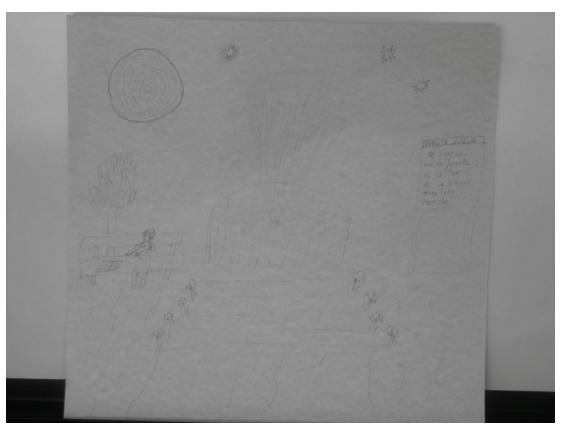

Imagen 1.1 La fuente

En la obra titulada: La herida ¿la huida del dolor? En este taller se trabajó con la tinta china, plumilla, diferentes formatos de cartulinas, purpurina. En un taller anterior, se trabajó con los mismos materiales pero con un cuentagotas en lugar de la plumilla. En estas obras pude percibir durante el proceso de creación un mayor riesgo y una menor búsqueda de imitación a otras personas o imágenes externas. El hecho de trabajar con un cuentagotas le impidió tener un dominio pleno de la materia y su manera de utilizarlo. Ello, le hizo sentir gran malestar, como cita ella: "he tenido que crear desde la imprevisibilidad de la tinta, he creado desde lo que me sugería, me he tenido que amoldar a ella". La interacción con la técnica y la consigna de la tarea, le hizo conectar con su tensión subjetiva vinculada a los materiales del arte; y ello le derivó a la participante a crear una imagen experimentando muchas dificultades para lograr sus propósitos. Los gestos del rostro y los movimientos del cuerpo, expresaban un gran malestar ante esta situación, que le impulsó el intentar probar otras soluciones para poder resolver las dificultades presentadas. Intentó 
pintar, poniendo el soporte de la obra en el aire, de tal manera, que con solo una mano pintaba y con la otra lo sostenía desde abajo. Esta nueva situación le produjo un aumento de tensión y de malestar, que le derivó a poner el soporte en la mesa y a aplastarlo con otra hoja. Al aplastar la tina, logra que ya no fluya por la cartulina, y una vez que la tinta ha quedado inmovilizada termina la composición. Estas actitudes a la hora de resolver dificultades en torno al material durante el proceso creativo, podrían ser pensados como procesos ilustrativos en relación a cómo posiblemente la participante, puede en determinadas situaciones, manejar las dificultades que le conecten con sus vulnerabilidades psíquicas y al mismo tiempo, no ser consciente de dichas estrategias para afrontar problemas. Uno de los rasgos comunes que expone (Gómez, 2007) en su práctica clínica con mujeres que sufren de fibromialgia, la presencia de tendencias en conflicto, de cuya existencia o contenido no se percatan, ya que son inconscientes y ante los cuales automáticamente procuran alcanzar ciertas soluciones de compromiso, pero que serán soluciones menos satisfactorias que las de un individuo "sano".

A partir de estos talleres, surgieron las primeras asociaciones libres sobre emociones experimentadas durante el proceso con otras situaciones de su vida. Pudo identificar el malestar con: "no tener el control", con el hecho de "tener que adaptarse" a la situación y con el malestar que siente de sufrir fibromialgia. Asoció "la reja como el dolor, las figuras como personas que huyen del dolor; el camino como la fibromialgia" y a nivel transferencial, podía recoger una gran resistencia, negación durante el discurso. El taller finalizó en el turno de palabra, y transmitió un discurso idílico en torno a la energía con la vida, la lucha y la resistencia de su trabajo personal para combatir su estado de malestar.

En el siguiente taller representó una fuente, la imagen respondía a una propuesta a través del material, "usar lápiz de escribir y goma". En esta obra se repitió la acción de copiar o imitar en la creación de la obra pictórica, (que ya encontrábamos en las primeras obras). Por un lado, coincide con otros estudios de casos de mi experiencia profesional y con la literatura encontrada, cuyos autores exponen que en una primera fase de su proceso de intervención, se caracterizó su proceso creativo por la necesidad de imitar en lugar de crear desde sí mismas. (Demeeker, 2007) expone en su trabajo con mujeres que sufren de reumatismo y fibromialgia, la importancia que el arteterapeuta tenga en cuenta estas premisas y permita al colectivo un periodo inicial largo solo para trabajar la creatividad.

Una de las dificultades manifestadas por diferentes profesionales en el campos de psicoterapias creativas, gira en torno a la creación de objetos resultantes desde uno/a mismo/a y por consiguiente, a conectarse a áreas psíquicas emocionales. Por ello, se podría decir que se percibe una tendencia de recurrir a la imitación, evitación, automatismo (hacer por hacer) y a abandonar la terapia. Según (Beck, 1975: 180187), y otros, hablan de la personalidad de los/as pacientes psicosomáticos/as, caracterizados por la negación de sentimientos, la represión de las necesidades y la sobre-adaptación a las normas externas. Actualmente, no se puede considerar el síndrome de la fibromialgia dentro de la clínica psicosomática, pero si se pueden relacionar ciertas similitudes. Desde mi punto de vista, la imitación, también puede 
ser pensada como un medio, mediante el cual, se puede poner en juego deseos de alcanzar una perfección o éxito en los resultados, evitando una conexión con la parte emocional vinculada a no alcanzar expectativas deseadas y al mismo tiempo se puede pensar como una resistencia.

Sin embargo, también he encontrado otros estudios de casos desde mi experiencia profesional y de otros profesionales (que no lo han publicado y no lo transmito como dato empírico sino como parte de una reflexión), donde las participantes, manifestaban un alto grado de creatividad y producción desde una fase inicial de la terapia. En algunos casos, la actitud predominante se caracterizaba por un "todo es perfecto", un "exceso de productividad", acatar literalmente la propuesta, donde las participantes trabajaban aparentemente muy bien. Considero que puede ser pensado como otro modo de actuar bajo deseos de "agradar y cumplir las expectativas del Otro", que les posiciona en un mismo lugar, evitar la conexión a sus propios deseos y actuar bajo dichas consignas.

Por último, para finalizar la reflexión sobre las diferencias entre los patrones hallados en los procesos creativos, de unos estudios de casos a otros, mencionar como posible causalidad: la singularidad, particularidad y complejidad del síndrome. La fibromialgia es un estado de malestar que aúna síntomas de diferentes enfermedades físicas y emocionales. Por tanto, la persona que lo sufre, no sufre solo fibromialgia, sino que sufren también según el caso: fatiga, artrosis, colon irritable, reumatismo, problemas estomacales, problemas en la vista, depresión, ansiedad, miedos, dificultad en el sueño, etc... Dependiendo el grado de sintomatologías que manifiesten de unos y de otros síntomas, la persona se acercará más al cuadro de la clínica psicosomática o del síndrome somático funcional. Por ejemplo: una persona que tienen conjuntamente reumatismo, se las consideraría según el DSM IV (manual de diagnostico de enfermedades) dentro del cuadro de la clínica psicosomático. La clínica psicosomática, se caracteriza por la dificultad de los/as participantes en conectar con la parte emocional. Pero, en el caso que las personas sufran de fibromialgia, depresión, dolor en zonas concretas sin causalidad orgánica, esté bajo un ambiente estresante, y presente alteraciones en el sueño, se alejaría de la clínica psicosomática y se acercaría a los procesos de somatización y la sintomatología de "las histerias ordinarias". En estos casos, los niveles de creatividad sería más elevados que en el ejemplo anterior y así mismo, disminuirían también las dificultades para trabajar.

La principal problemática reside, en que las personas que sufren el síndrome de la fibromialgia se caracterizan por una multisintomatología, y en mayor o menor grado vinculado a procesos de somatización, por lo tanto, según los grados de las sintomatologías específicas, influirán en las respuestas y las particularidades de proceder dentro del espacio del taller.

Retomando el espacio del taller, en el mismo taller de la imagen de la fuente, se incorporó una persona nueva llamada C. La participante A manifestó una necesidad de imitar a la compañera que llevaba más tiempo en los talleres. Mencionó en varias ocasiones que ellas eran "iguales". Pude percibir un deseo de ilusión de fundir identidades, y un malestar por parte de A, de sentirse amenazada ante la nueva per- 
sona que iniciaba los talleres. Según (Duró, J; Luz, M; López, L; Vignale, R, 2001) el "fenómeno de resonancia" hace referencia a un fenómeno que afecta a la gran mayoría de los/as participantes cuando hacen una obra, el resultado final de las obras se pueden parecer en la estética o en el contenido o en ambas cosas. Es muy habitual al inicio de los talleres un deseo o ilusión por parte de los participantes de ser todas iguales. La participante $\mathrm{C}$, sufre una enfermedad diferente al síndrome de la fibromialgia, pero muy parecida en la sintomatología del dolor. A y C se conocían de la asociación y mantenían una mala relación entre ellas desde hacía tiempo. En la imagen, llaman la atención las características estéticas: rigidez, simetría, estatismo, búsqueda del perfeccionismo, búsqueda del orden, imitación o copia de la imagen de la compañera, etc. (Demeeker, 2007) señala en su trabajo, la producción de una primera etapa de creaciones con estéticas marcadas por las características mencionadas y la autora lo interpreta como formas que poseen una tradición interna equivalente que ha servido a menudo como protección. (Shaverian,1991), en su investigación sobre la clasificación de tipos, funciones y valor de las imágenes, denomina "Imágenes Signos o Diagramaticales" expone, que es frecuente en una primera parte de los talleres, que las imágenes creadas no presenten una fuerte carga emocional; tienden a no coincidir el discurso de la participante acerca de lo creado con la imagen; tienen una función de establecer vínculos; ocupar un lugar dentro del taller; servirán como preámbulo para la creación de otras imágenes con mayor carga emocional. Podríamos pensar en esta obra como reflejo de una "defensa" ante la nueva participante que parece hacerle replantear a la participante sobre los roles dentro del grupo, también como una protección y al mismo tiempo, como parte del proceso del desarrollo creativo.

Lo más característico desde mi punto de vista, es la rigidez, la inmovilidad de la fuente, la cual, podría también representar la inmovilidad de su cuerpo, a merced de su entorno.

A raíz de este taller, en el turno de palabra, las participantes expresaron qué significaba para ellas sufrir la fibromialgia y cuáles podrían ser sus causalidades. La participante $\mathrm{B}$, decía:

proviene por un problema de estrés y también, que nacemos con un gen especial para saber qué es lo que otras personas necesitan, sin embargo, ellos no se dan cuenta; si yo estoy segura y sé lo que necesita pero la otra persona no lo quiere aceptar es cuando viene el problema...

La participante A, estaba de acuerdo con ella y además añadía su opinión personal cita: "no quiero controlar la vida de otras personas, como la de mi hermana, pero cuando no me cuenta las cosas y me las ocultan, me sienta mal. Yo hago las cosas sin esperar nada a cambio, pero cuando no me responden, me sienta mal".

Finalmente, C, aportaba una visión diferente, y les devolvía otra perspectiva que bajo su punto de vista, decía:

...el problema parte de vosotras, de vuestra dificultad de no poder soportar no tener el control de las cosas y en realidad, las buenas acciones que hacéis, es porque vosotras necesitáis hacerlas para sentiros bien con vosotras mismas, por vuestra propia necesidad, porque las otras personas, en realidad no lo necesitan... 
Este debate derivó a un enfrentamiento entre las participantes, quienes A y B no aceptaron lo que decía C.

(Shaverian, 1999) desarrolla el concepto de "Scapegoat" (chivo expiatorio) y expone que el mismo, se puede poner de manifiesto en los talleres: bien como obra que lo encarna o bien, como dinámicas dentro de un grupo, quienes desplazan su malestar a un miembro del grupo. La participante $\mathrm{C}$, a partir de este taller se convertirá en el chivo expia-

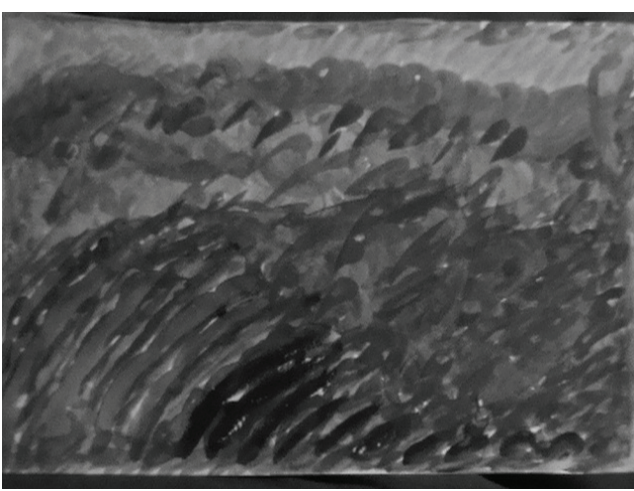

Imagen 2. Sentimiento torio.

Los rasgos estereotipados, fragmentados, simétricos, herméticos que son característicos en la primera fase del taller irán evolucionando a otras fases como se puede observar en la IMAGEN 2: "Sentimiento". En el desarrollo de esta obra percibí durante el proceso creativo una disminución en la tensión subjetiva.

Se abre un pequeño ciclo de propuestas con el material "acrílicos y acuarelas". En un primer taller de este ciclo, una de las consignas era pintar con las manos. La participante A, inicialmente rechazó ésta técnica, pero llevó a cabo la tarea y durante el transcurro del taller pude percibir conductas de hostilidad y agresividad desplazadas hacia las compañeras a quienes instruía en torno a: dejar limpio el material, no mezclar los colores, uso adecuado de los mismo, etc. Especialmente, expresaba una fuerte tensión interior, cuando algo "no estaba correctamente limpio, ordenado, en su lugar". En la asociación libre de ideas en torno a la identificación del malestar con aspectos biográficos, finalizó hablando de su relación con su hermana menor, a quien también le han diagnosticado de fibromialgia y a quien la participante, la definió como: "obsesiva de la limpieza". Exactamente citará: "No es que yo sea una extrema de la limpieza, como mi hermana, pero me gusta". Las negaciones como "No es que sea una obsesiva" o "No es para controlar", aparecían repetidamente a lo largo de los talleres, y se podría reflexionar en el concepto de la ambivalencia, y su relación con la personalidad en concreto de ésta participante pero también hallado en otros estudios de caso, donde encontramos sentimientos reprimidos, negados, conductas tendentes a tapar y mostrar reflejos contrarios y cómo a través del proceso creativo, se pone en juego o en relieve dichas dinámicas de procesos de formación psíquicos.

Conforme evolucionó el ciclo de taller, la técnica de pintar con acrílicos, le fue gustando. En concreto cita: "hemos empleado acuarelas, me ha gustado mucho la mezcla de colores y utilizar el pincel". He hecho una mezcla de colores, bien delimitados entre si'". Así poco a poco las resistencias presentadas por el material, que le permitían asociar a narrativas biográficas concretas marcadas por dificultades o tensiones sin tener una plena conciencia, se fueron convirtiendo en resistencias tra- 
bajadas mediante la expresión artística y transformadas en una estructura visual. Dicha estructura visual, podía tener un efecto cercano al concepto de "espejo" desarrollado por Lacan, que le permite a la participante recoger elementos estéticos que se relacionan a lo más genuino y propio de su subjetividad e iniciar, desde una observación en el espacio del taller, un rol más activo y consciente de su propia subjetividad.

En otro taller más avanzado, se trabajó con la arcilla y representó la escena de "una madre y una hija unidas por un vínculo". Desde que la participante A tenía siete años, su madre le había exigido afecto y amor absoluto. La madre, tras el nacimiento de su hermana pequeña había enfermado del corazón y tenía una delicada salud. Describe a su madre, como:

"mi madre era una persona obsesionada de la limpieza, del orden y una persona con falta de cariño por parte de mi padre"; "creo que intentaba llenar su falta de cariño a través de nosotras. Mi padre era una persona neutra, ni cariñoso ni atento...era..."

Ante las continuas quejas de la madre por tener la casa "perfecta", ella asumió responsabilidades como ejercer trabajos físicos muy fuertes (abrillantar suelos, cristales, limpieza de la casa, apoyar a su madre...), no propias para la edad que tenía, y en la libre asociación de ideas, recuerda su primer dolor muscular a la edad de siete años. Según (Gómez, 2007; Rodríguez, 2004; Demeeker, 2007; Beck, 1981) consideran la angustia y la hostilidad crónica inhibida en formaciones traumáticas infantiles como posibles desencadenantes en la formación del síndrome de la fibromialgia. (Barrera, M; Francisco, J; Guerrero, H; Aguirre, A, 2005) en una investigación de análisis cuali-cuantitativo, la información recogida del método cualitativo, en la metodología narrativa, aporta información relevante sobre el historial de infancia en las mujeres con dicho síndrome, marcado por el sufrimiento y por asumir un rol adulto desde temprana edad.

A través de este taller, me gustaría subrayar cómo ciertas dificultades manifestadas por la participante, estaban ya presentes desde el inicio del trabajo en grupo, y las mismas giraban en torno al malestar cuando "no tenía un control" o "la manera de trabajo no era lo suficientemente limpio y ordenado", etc. En esta investigación se tiende a promover la asociación libre de emociones con otros fragmentos de su novela familiar. La participante A, referenció en un primer lugar a la hermana y en ésta última obra, ha referenciado a la madre. Invito a pensar nuevamente en el concepto (Shaverian, 1999) "scapegoat", en el cual, un sujeto puede encarnar "algo" como propio, pero que en realidad no le pertenece, procede de otras personas, que han desplazado una carga emocional y que el sujeto, finalmente lo integra como propio. A lo largo de su experiencia vital, puede manifestarse estados subjetivos de subordinación y alienantes hacia "eso" que Otro depositó, y tener un efecto estigmatizador, castigador, causando malestares en el estado emocional.

Uno de los objetivos de ésta investigación acción es detectar y recoger información en relación a conflictos inconscientes y en relación también al uso del cuerpo como mediación donde se deposita y se evidencia, la somatización. Desde éstas premisas, se trata de idear unas acciones basadas en el arte, que les permita a las 
participantes confrontar con su tensión subjetiva en relación con los materiales de arte, el proceso creativo y la creación de imágenes, y posibilitar un espacio donde se pueda identificar, relacionar y reflexionar áreas de malestares psíquicos, para acercarlas a un estado de conciencia. Para ello, siempre les pregunto a las pacientes como pueden asociar y relacionar el malestar producido en los talleres y que significado creen que puede tener en su vida actual y en qué medida les afecta en relación al dolor. (Hogan, y Malchiodi, 1997:49), fundamenta los beneficios a una de las características principales de la terapia, y es, que ofrece un espacio para expresar, reaccionar ante determinadas emociones, construir y reconstruir las historias y las experiencias vitales.

En el taller titulado "vitalidad y fuerza". El proceso se caracterizó por dedicarle la mayor parte del tiempo en mezclar los colores antes de iniciar el acto de pintar, como si hubiese emprendido una lucha con los pigmentos y se pelease con ellos hasta lograr la mezcla deseada. Después realizó la tarea de una manera agitada, convulsa, con fuerza, estrepitosamente. Parece que la liberación de la energía provocada por la técnica le permitió adentrarse en una riqueza de su mundo interior. A través de la imagen hablaba de necesidades personales en relación al Otro, y cómo esas necesidades influían directamente en la intensidad del dolor físico. El arteterapia proporcionó un entorno, en el que ella fue capaz de expresar elementos de agresión durante el proceso creativo, así como expresar necesidades, vulnerabilidades y exponerlas al grupo de una manera abierta.

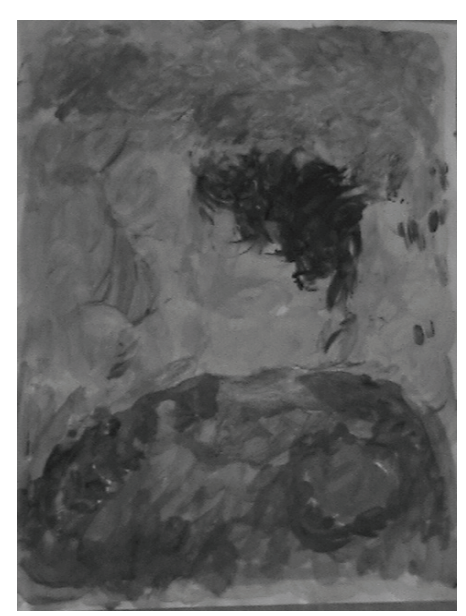

Imagen 3. Cuerpo y mente

A partir de este taller empezó a pintar en su casa por cuenta propia. En varias ocasiones mencionó: "cuando estoy en casa, en el sofá me pongo a pintar, me relaja, me da tranquilidad, paz interior y no siento el dolor en el cuerpo".

En la IMAGEN 3, llamada "cuerpo y mente" se trabajó con una variedad de materiales, acrílicos, pinturas de manos, óleos, agua, papel higiénico, purpurinas, música, papel continuo, cartulinas, papel de seda. En esta obra, se repitieron los mismos temas y colores que en obras anteriores, donde asociaba colores con emociones, tal como: verde-esperanza; amarillo-amistad; rojoemociones; morado/violeta, antes significaba lo relacionado a la mujer, feminismo, ahora, representaba el dolor. Hablando de los colores tomó conciencia de un ejemplo que ella había contado en otro taller acerca de la percepción del dolor, citó: "Hay días muy malos que sentía el cielo en la cabeza". La imagen le devolvía un reflejo de esa expresión, a través del color azul-cielo, un cielo que le aplastaba la cabeza. También, reflexionaba acerca del color morado que representa el dolor, dicho color estaba representado en partes del cuerpo específicas que creía haberlo hecho al azar y sin embargo, estaban representados en los puntos donde actualmente son de mayor intensidad. Dedicó la parte final del taller a obser- 
var detenidamente su obra, y poco a poco iba adquiriendo conocimientos sobre la relación de dolor a causa de una separación entre las emociones y la mente. El color rojo, lo denominaba como la intensidad emocional, y ella expresaba mediante la imagen, las dificultades que encontraba en poder pensar las emociones. Cita: "Yo observo que otras personas sufren menos que yo, soy muy impulsiva y emocional". La imposibilidad de una elaboración consciente de las emociones, no supone una eliminación de ellas, sino que por lo contrario, el cuerpo, se convierte en un contenedor de ellas y a través del dolor, puede revelar las huellas de la represión.

Para la participante fue una sorpresa, asociar tantos elementos de la obra con aspectos emocionales propios y sentir una identificación en la imagen. Podemos observar, que mediante el arteterapia, la participante encuentra nuevas maneras de comunicar, a través del lenguaje del arte y con el apoyo emocional de la arteterapeuta, pueden verse a ella misma, simultáneamente, como creadora y persona que aprende. Ello le posibilita adquirir habilidades, conocimientos sobre sí misma y su mundo. A ese apoyo emocional es denominado por (Kramer, 1979) como la "alianza terapéutica", para caracterizar la relación entre paciente y arteterapeuta. En este taller el alivio de dolor fue considerablemente alto, dato expresado por la participante al final del mismo.

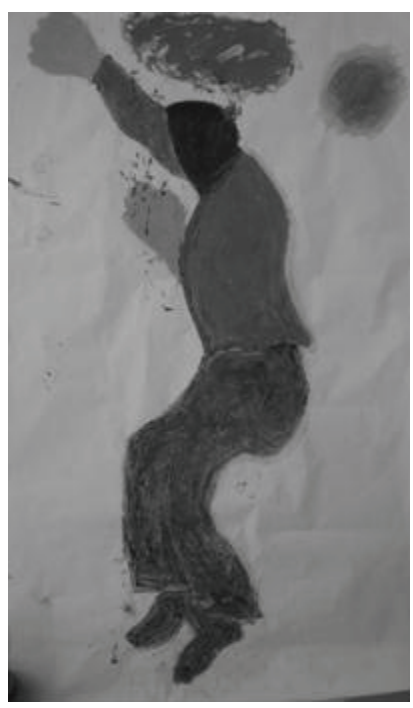

Imagen 4 Cuerpo 1

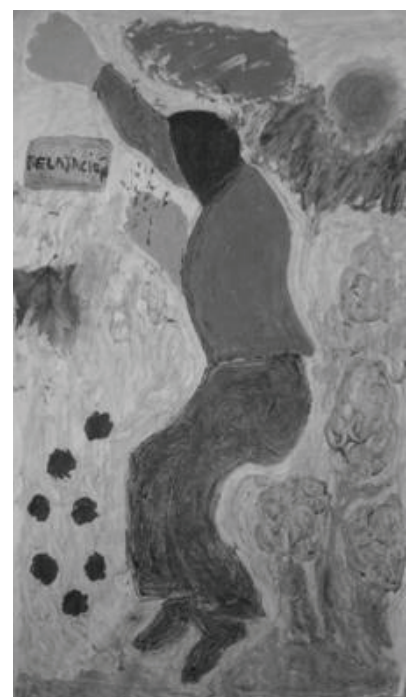

Cuerpo 2

Adentrándonos en la parte final del proceso arteterapéutico, las propuestas de trabajo fueron especialmente simbólicas. En el siguiente taller, se trabajó con la consigna del cuerpo. (IMAGEN 4: CUERPO 1 Y 2). Una compañera pintaba el límite del cuerpo de otra compañera. La persona a quien se pintaba se tumbaba en el suelo, encima de un papel continuo y escogía libremente la postura. Este proceso se iba haciendo para cada una de las participantes. La propuesta específica era que trabajasen el cuerpo tanto por dentro como por fuera. En el desarrollo creativo del 
trabajo interno del cuerpo, la participante manifestaba una expresión de relajación, tranquilidad, estar concentrada a la tarea de trabajo, conectada en el "aquí y ahora" que acontece, disfrutando de su proceso, y en un momento determinado, empezó a pintar un límite grueso a lo largo de todo el cuerpo. Observar la creación de ese "límite" desde su postura serena, podríamos pensar, en el concepto de la "ambivalencia" que normalmente acompañaba en fragmentos de la vida de la participante, recoger una sugerencia de una paz externa y al mismo tiempo, una actitud interior con cierta agresividad, resistencia, límites, agitación, pesadez en la cabeza y soledad que surgió a través de su enfermedad.

He de mencionar que el proceso de pintar la parte exterior del cuerpo fue antagónico a la parte interior. Cuando pintó la parte exterior, el proceso estuvo especialmente marcado por un estilo agitado, convulso, escogió libremente pintar con las manos (técnica que rechazaba), nerviosa, llegó a hacerse finalmente daño en el brazo.

A raíz de estos talleres, la autora abrió un dialogo interno, una reflexión en torno a ¿porqué otras personas no sufren los conflictos emocionales en el cuerpo y porque yo sí somatizo?. Preguntas en torno a la gestión de las emociones y en torno a ¿en qué lugar me posiciono yo y en qué lugar se posicionan los otros y en qué lugar me posicionan? Estos interrogantes surgieron por parte de la participante, cuando ella reflexionaba sobre lo experimentado durante el proceso creativo del cuerpo interior, y lo relacionaba a cómo se encontraba ella cuando estaba consigo misma, podía estar tranquila; y reflexionó también sobre lo vivenciado durante el proceso creativo del cuerpo exterior, y lo relacionó con las relaciones familiares, las relaciones sociales, y cómo las mismas, le conducían a discusiones sobre dificultades en torno al establecimiento de los límites y en función de cómo piensa ella y como piensan los otros y esa imposibilidad de llegar a acuerdos, le conducía a estados emocionales negativos que al mismo tiempo, le afectaba en la intensidad del dolor corporal.

Desde un enfoque psicosomático, (Denneeker, 2007) dice que existe un círculo vicioso entre acción, emoción y tensión muscular. Se podría reflexionar en la posibilidad de desencadenamiento por factores ambientales y psicogenéticos, que podrían hacer conectar con conflictos inconscientes y dicho círculo vicioso, podría posicionar al sujeto en una subjetivad pasiva. Así, uno de los efectos terapéuticas del arteterapia, desde el inicio de los talleres, es la creación de imágenes, que permite a la participante desarrollar un rol activo, y adquirir progresivamente una mayor conciencia de la relación entre el dolor físico y ciertos acontecimientos específicos exteriores. Mediante el arteterapia, se ofrece un espacio para "pensar" en el cuerpo, en el dolor y posibilitar mediante la "actuación a través del arte" una estrategia expresivas alternativas a la somatización. 


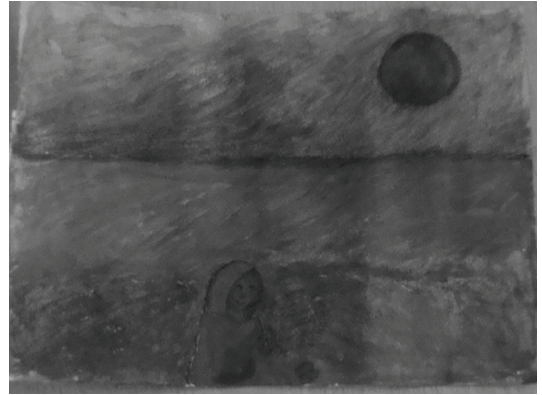

Imagen 5. Juntas podemos vivir la vida

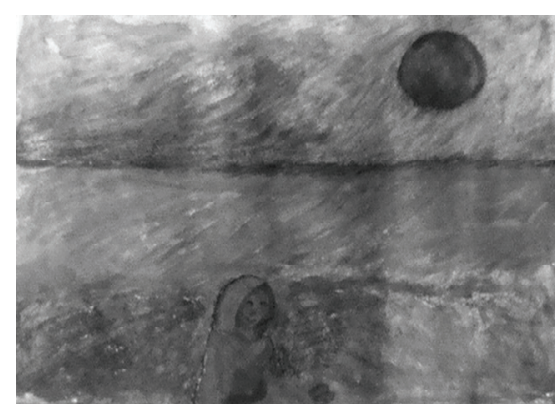

Imagen 5.1 Mujer Hermita

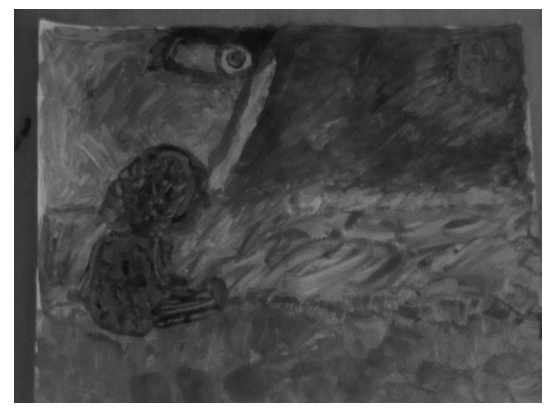

Imagen 5.2 Meditando

Las obras finales están marcadas por la creación de imágenes cuyos valores estéticos manifiestan unas características más integradas, equilibradas y unificadas. La participante vuelve a traer la representación de diferentes emociones que durante los talleres anteriores aparecían de manera repetida, fragmentada, pudiendo observar ahora una evolución de las mismas. En la imagen 5, la denominó "Juntas podemos vivir la vida". A lo largo de los talleres la participante acentuó el interés por aprender cuestiones técnicas y deseos de recibir críticas objetivas de su trabajo. La relación terapéutica fue definida por el proceso de arte, el lenguaje del arte se convirtió en el estímulo para el contenido de la comunicación verbal. Y otro fenómeno a destacar de los efectos de la creatividad artística en ésta participante es la posibilidad de recibir "gratificación narcisista". Se trata de un término descrito por (Numburg, 1966), como el acto creativo por el cual una persona es capaz de experimentar el reconocimiento y la competencia no vinculado al conflicto o perturbación interior. El hecho de no envidiar a otros y trabajar para sí mismos y expresar deseos abiertamente es una tarea difícil para muchos sujetos con características psicosomáticas.

La participante sintió un gran orgullo y satisfacción de esta obra y decidió regalarlo al centro y lo colgó en el lugar más visible de la asociación para que todo el mundo pudiese contemplar su trabajo en los talleres de arteterapia. Por otro lado, como apunta (Omenat, 2006),

...El regalo puede ser pensado para hacer perdurar el recuerdo del grupo de arteterapia o lo que se dio en él. Puede haber la fantasía en estos grupos de corta 
duración, que una vez finalizado puede desaparecer también la experiencia de él. La obra personal transciende al grupo y con el regalo deja constancia a otras usuarias del centro, de su presencia por él.

He de remarcar que la creación de las obras finales, tuvieron lugar desde la iniciativa por parte de la participante, que en su tiempo de ocio, y a raíz de unos beneficios experimentados durante las sesiones de los talleres, decidió integrarlo en la cotidianeidad de su vida. Su curiosidad por aprender la técnica fue incrementándose, y el motivo de pintar, fue tal y como ella citó: "Me gusta jugar y explorar mi mundo interior". (Winnicott, 1985) postula un espacio por el cual poder jugar y en este espacio potencial ubica la relación entre el cuerpo y la mente, conectando el mundo interior con la realidad externa: "Jugar es una expresión y premisa para la salud, conduce a las relaciones del grupo social y es una forma de comunicación". (pag 52)

En la imagen (5.1) "Mujer Hermita" y la imagen (5.2) "Meditación", me parecían en primer lugar de un valor notable en la medida en que la participante, creaba una imagen, en la cual, se repetían una serie de elementos anteriores, entre ellos los colores azul y rojo, a los cuales, en el pasado, les asignó un significado emocional y ahora, los representaba, desde una estética más integrada. En la imagen "Mujer Hermita", el azul se degrada por toda la composición, y en la imagen "Meditando", ese "azul" que aparecía como un peso o imposición sobre su cabeza, ahora podría ser materializado en el ojo, al que ella, desde otra posición, mira de frente. Desde mi punto de vista, estas imágenes son marcadamente encarnadas y nos podría acercar al pensamiento del concepto de duelo, y pensar también en la posibilidad de cómo la participante, a través de la creación y observación de sus propias obras, ha podido reflexionar sobre ciertas dificultades subjetivas relacionadas a significantes "alienantes" y crear nuevas imágenes que tanto en la obra como ella como creadora, ha podido expresarlas desde una posición más "separada".

\section{CONCLUSIONES}

Considero que es un caso con resultados satisfactorios, en la medida en que puede responder positivamente al cumplimiento de la tarea y a la hipótesis de trabajo establecida. En torno a la tarea, ha trabajado su creatividad hasta niveles altos de expresión. Ha creado símbolos, mediante representaciones visuales que ilustran condiciones internas y externas de sus emociones.

En relación a la hipótesis de trabajo, se puede responder que:

Efectivamente, en este estudio de caso, el arteterapia, puede ser una alternativa terapéutica eficaz a un tratamiento médico, e igual de válida a otros tratamientos para el alivio de la sintomatología del dolor.

Se ha logrado de manera satisfactoria, uno de los objetivos principales de la metodología de estudios de casos, en la cual, se esperaba obtener información narrativa y su posibilidad para relacionarla con los paradigmas de las teorías: psicoanalíticas, psicosomáticas y de género. 
A lo largo de su proceso se permitió tomar riesgos para experimentar e ir más allá de las resistencias y explorar su mundo interior y fantasías. El juego, le posibilitó conectarse a algo saludable que la misma participante identificó y le derivó a extrapolarlo fuera de los talleres, por los beneficios en torno al alivio de dolor experimentado.

Mediante la observación de sus obras, ha podido identificar elementos estéticos y relacionarlos con estados de malestar. Establecer una distancia y un diálogo con la obra en el espacio del taller, le ha posibilitado trabajar conflictos inconscientes y simbolizarlos.

A través de la asociación libre de ideas, le permitió identificar actitudes, emociones y conductas dentro del taller y relacionarlos con circunstancias vitales externas a dicho espacio y tomar conciencia de sus consecuencias en relación a la sintomatología del dolor. Todo ello, le ha permitido desconstruir narrativas fijadas y abrir nuevas posibilidades, construir otras narrativas.

Así mismo, ha podido identificar aspectos de su subjetividad en conflicto y resinificarlos, como: el valor a los colores, su relación a las emociones, su relación a la somatización y cómo los mismos se han ido transformando conforme evolucionaba el taller.

El grupo de arteterapia, le permitió mejorar las relaciones sociales, reconocer ciertas características propias de la fibromialgia y contrastarlas con otra participante que no tenía la misma enfermedad y una perspectiva diferente a la suya sobre la causalidad de la misma, y progresivamente la relación entre ambas fue mejorando, y le posibilitó aceptar nuevas ideas en torno a núcleos de sufrimiento relacionados al síndrome.

La participante, a través de su trabajo en los talleres de arteterapia, ha podido relacionar aspectos del síndrome que afectaban directamente al dolor en el cuerpo, ha podido detectar conflictos subjetivos vividos con negatividad y con sufrimiento interior y ha reflexionado sobre los procesos creativos en relación a su malestar y por consiguiente, ha podido ampliar su posición subjetiva.

Los principales factores que han contribuido a la evolución favorable del estudio de caso:

Espacio de comunicación, la alianza terapéutica, el grupo, los materiales de arte y los procesos creativos. Estos factores han sido beneficiosos para la participante para poder identificar sentimientos y emociones experimentados con otras áreas de su vida y trabajarlos en un espacio seguro y de contención. Todo ello se evidencia en la evolución de su discurso, donde parte de una posición subjetiva inicial caracterizada por: la rigidez, intolerancia, malestar, autoeolgío, imposición al grupo, agresividad, etc...a otra, más flexible, abierta, empática, activa y ampliada de lo que le acontece y su relación directa con su presente.

A través de la acción creadora ha reforzado aspectos en torno al narcisismo, ha experimentado una mayor seguridad, satisfacción y orgullo de sí misma. Conforme evolucionaron los talleres se incrementaron sus deseos de aprender la técnica para poder expresar mejor sus ideas y dicho interés partió, tal y como citó ella en su diario por: "Me gusta jugar y explorar mi mundo interior". 
La participante, tanto en su diario artístico como en cuestionario y entrevista semiestructurada a mitad y final de los talleres, como verbalmente, afirmó haber experimentado alivio y beneficios en la sintomatología del dolor en el transcurro de los talleres de arteterapia.

Se puede decir que en este estudio de caso, el arteterapia es una estrategia alternativa a la somatización de dolor en el cuerpo, evitando a la participante sentir dolor, mientras se conecta con la acción creadora.

\section{REFERENCIAS BIBLIOGRÁFICAS}

BARRERA, M; FRANCISCO, J; GUERRERO, H; AGUIRRE, A, (2005): “Análisis cuali-cuantitativo. Salud Mental" ¿La fibromyalgia un syndrome somatic functional o una nueva conceptualization de la hysteria?. Dic Año-Vol 28, num 006. Instituto Nacional de Psiquiatría Ramón de la Fuente, Distrito Federal, México, pp 41-50.

BECK, D. (1975) "Die personlichkeitsstruktur bei psychosomatischen schmerzzustanden des bewegungsapperates". Psychosomatische schmerzsyndrome des bewgungsapperates In A. Weintraub et al. Ed pp(180187). Basle: Schwabe.

DENNECKER, K (1991)."The American Journal of Art therapy”, Vol. 29, May.

DURÓ,J; Ibañez,M; López,L; Vignale,R; (2008) Dispositivos grupales salud mental comunitaria Master Arteterapia. Departamento de psicología de la Universidad de Murcia.

FLYBJERG, B (2006) Five Misunderstandings About Case-StudyResearch. Vol 12. $\mathrm{N}^{\circ} 2$. Sage publication. Dinamarca

GÓMEZ, P (2009): "Una guía para pacientes y terapeutas" Fibromialgia cómo vencerla desde el cuerpo y la mente. Ed Integral. Barcelona.

KRAMER, E (1979). “Childhood and art therapy”. New York: Schocken Press. PP 186.

MALCHIAODI, 1997 C. Malchiodi, "Art as empowerment for women with breast cáncer”. In: S. Hogan, Editor, Feminist approaches to art therapy, Routledge, London pp. 49-64.

NAUMBURG, M (1996). Dinamically oriented art therapy. Chigaco: Magnolia Street.

OMENAT, MONTSE (2006) Arte terapia con mujeres que han sufrido violencia de género: Valor y uso del objeto artístico en Arte terapia, 225-261. Murcia. Universidad de Murcia. 
SHAVERIAN, J (1987) y T. DALLEY (1991) The scapegoat and the talisman: transference in art therapy. InImages of Art Therapy, eds. The Reveling Image: analitical art psycotherapy in theory and practice, London, Jessica Kingsley Publishers.

WINNICOTT, D. (1985). Vom spiel zur kreativitaet. Stuttgart: Klett-Cotta. 